Bachrach U. (1957). J. gen. Microbiol. 17, 1-11

\title{
The Aerobic Breakdown of Uric Acid by Certain Pseudomonads
}

\author{
BY U. BACHRACH* \\ Department of Microbiology, The University of Reading
}

SUMMARY: Four pseudomonad isolates which could use uric acid aerobically as a sole $\mathbf{C}, \mathbf{N}$ and energy source were isolated from poultry house deep-litter, droppings, and nearby soil. Organisms harvested from media containing uric acid can degrade uric acid completely, with the formation of $\mathrm{CO}_{2}$ and $\mathrm{NH}_{3}$. Allantoin, allantoic, glyoxylic and formic acids were completely oxidized.

The existence of micro-organisms able to decompose uric acid aerobically has long been known (see Stapp, 1920), but relatively little work has been reported on the biochemical pathways of this decomposition. The excrement of chickens contains a relatively large amount of uric acid (c. $5 \%$ of the dry weight, depending somewhat on the diet; information kindly supplied by Dr. J. Tinsley). In the deep-litter method of poultry husbandry the uric acid of the droppings rapidly disappears from the litter and there is often a marked evolution of ammonia. It seemed likely therefore that established deep-litter beds in poultry houses might well be a habitat from which micro-organisms capable of decomposing uric acid could easily be obtained; this proved to be so. It was decided to seek aerobic organisms which could use uric acid aerobically as sole source of carbon, nitrogen and energy in order to obtain microorganisms with a rich array of enzymes capable of affecting uric acid. Elective cultures yielded bacteria which grew aerobically on a uric acid + mineral salts medium.

The decomposition of uric acid by these organisms was then explored by examining their $\mathrm{O}_{2}$ uptake with uric acid and various related compounds which have been implicated in biological degradation of uric acid, as substrates. These compounds are shown in Fig. 1, which indicates a pathway of uric acid decomposition compatible with the evidence so far obtained with the pseudomonads used in the present work. The existence of enzymes which catalyse some of the chemical steps in the pathway shown in Fig. 1 is well known (see Laskowski, 1951), one or more of these enzymes having been observed in many different forms of life. The pseudomonads isolated in the present work are able to carry the aerobic degradation of uric acid the whole way to carbon dioxide and ammonia. This paper reports a preliminary examination of their metabolism of uric acid.

\footnotetext{
* Present address: Department of Clinical Microbiology, Hebrew University-Hadassah Medical School, Jerusalem, Israel.
} 
<smiles>CC(NC(N)=O)C(NC(=O)O)(NC(=O)NC(NC(=O)O)C(=O)O)C(=O)O</smiles>

Uric acid

HDC*

Allantoin<smiles>NC(=O)NC(NC(N)=O)C(N)=O</smiles>

Allantoic acid

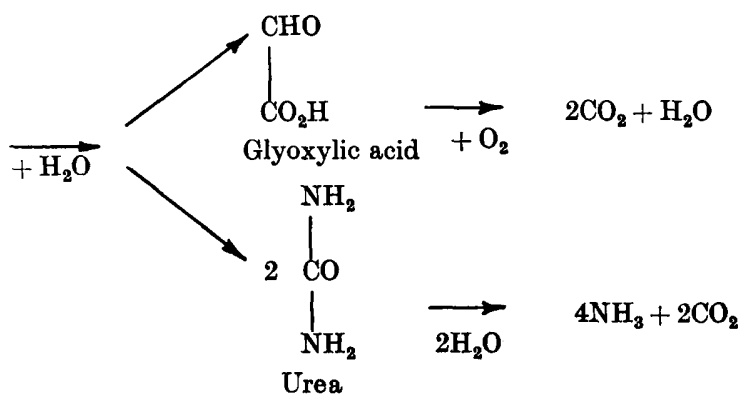

Fig. 1. Probable pathway of aerobic breakdown of uric acid by the pseudomonads used. Overall reaction: $\mathrm{C}_{5} \mathrm{H}_{4} \mathrm{~N}_{4} \mathrm{O}_{3}+3[\mathrm{O}]+4 \mathrm{H}_{2} \mathrm{O} \rightarrow 5 \mathrm{CO}_{2}+4 \mathrm{NH}_{3}$. ${ }^{*} \mathrm{HDC}=$ compound made by the method of Schuler \& Reindel (1932); for systematic name see Dalgleish \& Neuberger (1954).

\section{Isolation and characterization of organisms}

The elective medium. This was made as follows: a solution of $5 \mathrm{~g} \cdot \mathrm{KH}_{2} \mathrm{PO}_{4} /$ $100 \mathrm{ml}$. tap water, adjusted to $\mathrm{pH} \mathrm{7 \cdot 3-7 \cdot 5}$ by adding $\mathrm{NaOH}$ solution was filtered and autoclaved at $15 \mathrm{lb}$./sq.in. for $20 \mathrm{~min}$. Sterile uric acid powder (sterilized by heating at $160^{\circ}$ for $1 \mathrm{hr}$.) was then added aseptically to the phosphate solution to a final concentration of $c .0 .5 \mathrm{~g} . / 100 \mathrm{ml}$, the liquid being shaken to disperse the powder. This suspension was then dispensed aseptically in $10 \mathrm{ml}$. vol. into sterile 6 in. $\times 1$ in. rimless tubes closed by loosely fitting aluminium caps (Oxoid).

Samples were taken at the poultry research unit maintained at its Lane End Farm by the Department of Agriculture (University of Reading) as follows: deep-litter (from below the surface); droppings on the deep-litter; soil from the field surrounding the poultry houses. Portions of these samples were added to tubes of the elective medium which were sloped to give maximum exposure to air and incubated at $25^{\circ}$.

After four serial subcultures in elective medium, cultures were plated on solid medium of the basal composition described by Stapp (1920); this contained agar, uric acid, potassium and sodium phosphate, calcium chloride, magnesium sulphate, sodium chloride, ferric chloride, made up in distilled water. Colonies were picked and inoculated to the uric acid + phosphates liquid medium in tubes. Subcultures were made in the same medium to 
establish that the organisms so obtained could grow aerobically in serial subculture in a medium which contained effectively only uric acid as source of C, $\mathbf{N}$ and energy. Eventually four isolates were so obtained (one from soil, 2 from deep litter, 1 from droppings) and were examined for their bacteriological characters.

Characters of the isolates. The four isolates (A, B, C, D) showed the following characters: Gram-negative; motile; polar flagella; rods (except D which was cocco-bacillary); indole-negative; Voges-Proskauer negative; gelatin not hydrolysed (5 days); litmus milk alkaline (7 days) no clotting; non-lipolytic (margarine, tributyrin). Sugars in general gave no acid or gas, though isolates $\mathrm{B}$ and $\mathrm{C}$ gave acid with glucose. Nitrate was reduced to nitrite by isolates $\mathbf{A}$ and $\mathbf{C}$. Isolates $\mathbf{B}$ and $\mathbf{C}$ gave a greenish fluorescent water-soluble pigment; $A$ and $D$ did not. Growth was very poor or absent at $37^{\circ}$ with isolates $A, B$ and C, while isolate D grew fairly well; there was no growth at $40^{\circ}$. They were classified as species of Pseudomonas, and not further characterized; they are clearly closely related. In the metabolic work not all four isolates were always used, but in replicate experiments with different isolates usually no essential differences were observed.

\section{Materials and methods used in the metabolism experiments}

For the metabolic studies organisms were usually grown on a complex medium containing uric acid, in order to obtain larger yields of organisms than those given by growth in the minimal uric acid + mineral salts medium. No marked differences were observed between the organisms grown on the two kinds of media. The complex medium consisted of: peptone (Evans), 10 g.; yeast extract (Oxoid), 3 g.; NaCl. 7.5 g.; agar (Kobe), 20 g.; $1000 \mathrm{ml}$. tap water; adjusted finally to $\mathrm{pH} \mathrm{7 \cdot 4}$. Sterile powdered uric acid to final concentration $0.2 \%(\mathrm{w} / \mathrm{v})$ was mixed into the molten agar to give a uniform suspension. This medium when solidified in the Petri dishes was opalescent, and the disappearance of uric acid during growth of the pseudomonads could be noted by the appearance of clear zones surrounding colonies. After $24 \mathrm{hr}$. of incubation at $25^{\circ}$ the uric acid had disappeared and the organisms were collected, washed three times with $0 \cdot 85 \%(\mathrm{w} / \mathrm{v}) \mathrm{NaCl}$ solution and resuspended at a suitable concentration in the same solution. These suspensions were stored when necessary at $-20^{\circ}$, for not longer than 1 week. The concentrations of the suspensions used are noted in the Tables.

Substrates. Uric acid was used as the lithium salt (Davidson, 1938); allantoin as the potassium salt (Young \& Conway, 1942); allantoic acid was prepared from allantoin according to Hermanowicz (1948). The compound intermediate between uric acid and allantoin (see Fig. 1) is called 'hydroxyacetylene-diureido-carboxylic acid' in the earlier literature; its systematic name is given by Dalgleish \& Neuberger (1954). It will be referred to here as HDC; the sample used was prepared from uric acid according to Schuler \& Reindel (1932). Glyoxylic acid was supplied by Light and Co. (Poyle Estate, Colnbrook, Bucks); the purines were from Roche Products Ltd. (Welwyn Garden City). 
Analytical procedures. Oxygen uptake and $\mathrm{CO}_{2}$ output were measured by conventional Warburg manometric techniques with air as gas phase and bath temperature $30^{\circ}$ (Umbreit, Burris \& Stauffer, 1949); the 'direct' method of Warburg was used for $\mathrm{CO}_{2}$ and correction was made for bound $\mathrm{CO}_{2}$ by tipping acid at the end of the experiment. All manometric data quoted have been corrected for the endogenous rates.

For estimating various products the following analytical methods were used: uric acid by the method of Praetorius (1949) with a Unicam UV spectrophotometer (SP 500); purines spectrophotometrically (Hotchkiss, 1948); allantoin by the colorimetric method as modified by Franke, Taha \& Krieg (1952); allantoic acid by the method of Di Carlo, Schultz \& Kent (1953); glyoxylic acid as for allantoin but with the omission of the first step; ammonia by titration (Ma \& Zuazaga, 1942) after steam distillation in a Markham still (Markham, 1942); urea by estimation of ammonia after treatment with urease; volatile fatty acids by steam distillation (Markham still) followed by titration of the distillate with $0.01 \mathrm{~N}-\mathrm{NaOH}$ (phenolphthalein as indicator). Glyoxylic acid was identified by paper chromatography after its conversion to the corresponding 2:4-dinitrophenylhydrazone (Block, Durrum \& Zweig, 1955); the solvent was butanol:ethanol:0.5 N- $\mathrm{NH}_{4} \mathrm{OH}(70: 10: 20$ by vol.). The $\boldsymbol{R}_{f}$ value for glyoxylic acid was $\mathbf{0 \cdot 3 8}$.

\section{Results of metabolism experiments}

\section{Oxidation of uric acid and related compounds by rhole organisms}

Adaptive enzymes. Preliminary experiments showed that the ability of the pseudomonads to decompose uric acid was not a constitutive property. Organisms grown on peptone water or on yeast-extract agar without added uric acid, oxidized uric acid only after a lag period (e.g. $120 \mathrm{~min}$.). When these media were supplemented with uric acid $(0 \cdot 2 \% \mathrm{w} / \mathrm{v})$ the organisms so obtained oxidised uric acid without lag. The oxidation of uric acid by washed organisms was optimal at $c . \mathrm{pH} 7 \cdot 4$. All subsequent experiments were carried out in the presence of $\mathrm{M} / \mathbf{1 5}$ tris buffer at $\mathrm{pH} 7 \cdot 3-7 \cdot 5$; similar results were obtained when phosphate buffer was used.

Uric acid as substrate. The degree of oxidation of uric acid and of some possible metabolic intermediates by uric acid-grown organisms is illustrated in Table 1. In every case about 3 atoms of oxygen were taken up for every mole of uric acid which disappeared. Estimation of urea at the end of experiment showed that about $2.3 \mu$ mole were left from $2.5 \mu$ mole of uric acid decomposed, thus, together with $9.9 \mu$ mole of $\mathrm{CO}_{2}$ formed, accounting for all the carbon atoms present in the uric acid molecule (Table 2). In a larger scale experiment with $20 \mu$ mole uric acid and an amount of pseudomonad A equivalent to $c .60 \mathrm{mg}$. dry wt., the ammonia and urea formed during $6 \mathrm{hr}$ were determined. The absorption spectrum showed that all the uric acid had disappeared; half the nitrogen of the uric acid appeared as ammonia and the other 2 atoms of nitrogen were accounted for as urea (Table 2). No volatile fatty acids were formed during this experiment. 
Table 1. Oxygen uptake by the uric acid-grown pseudomonads studied in presence of various substrates. Summary of results

Each Warburg vessel contained $0.5 \mathrm{ml}$. substrate solution; $1.0 \mathrm{ml}$. of suspension of organisms (equivalent to $3-5 \mathrm{mg}$. dry wt.); $1.0 \mathrm{ml}$. of tris buffer $\mathrm{pH} 7 \cdot 3 ; 0.2 \mathrm{ml}$. of $15 \%(\mathrm{w} / \mathrm{v}$ ) KOH in centre well; total volume $3.2 \mathrm{ml}$. The gas phase was air. The values have been corrected for endogenous activity.

\begin{tabular}{|c|c|c|c|c|}
\hline & \multicolumn{4}{|c|}{ Strain of pseudomonad } \\
\hline & $\mathbf{A}$ & $\mathbf{B}$ & $\mathbf{C}$ & $\mathbf{D}$ \\
\hline Substrate ( $\mu$ mole) & \multicolumn{4}{|c|}{$\mathrm{O}_{2}$ uptake $(\mu$ mole $)$} \\
\hline Uric acid, 5 & $7 \cdot 4$ & $7 \cdot 0$ & $7 \cdot \mathbf{3 5}$ & $6 \cdot 9$ \\
\hline Allantoin, 5 & $4 \cdot 2$ & - & - & - \\
\hline Glyoxylic acid, 5 & $4 \cdot 6$ & $\mathbf{5} \cdot \mathbf{3}$ & 4.75 & $5 \cdot 2$ \\
\hline Formic acid, 10 & 4.75 & $\mathbf{5} \cdot \mathbf{1}$ & $4 \cdot 85$ & $5 \cdot 15$ \\
\hline
\end{tabular}

Intermediate compound $H D C$. Schuler \& Reindel (1932), when studying the oxidation of uric acid by alkaline permanganate, isolated the silver salt of a symmetrical compound which was probably the intermediate compound HDC (see Fig. 1.). Subsequently, Cavalieri \& Brown (1948) showed, by labelling the nitrogens of the pyrimidine ring of uric acid, that a symmetrical intermediate was formed during the oxidation of uric acid with alkaline permanganate. Klemperer (1945) suggested that a symmetrical compound might be obtained by the action of liver uricase on uric acid, and Brown, Roll \& Cavalieri (1947) showed, by feeding rats with labelled uric acid, that the in vivo oxidation of uric acid involved a symmetrical intermediate.

Table 2. Products of oxidation of uric acid and glyoxylic acid by pseudomonad $A$ grown in presence of uric acid

Experimental conditions as in Table 1, but for $\mathrm{CO}_{2}$ estimations $0.2 \mathrm{ml}$. of $2 \mathrm{~N}-\mathrm{HCl}$ was tipped from side arm, and distilled water was in centre well.

$\begin{array}{lcccc}\text { Substrate }(\mu \text { mole }) & \begin{array}{c}\mathrm{O}_{2} \text { taken up } \\ (\mu \text { mole })\end{array} & \begin{array}{c}\mathrm{CO}_{2} \text { evolved } \\ (\mu \text { mole })\end{array} & \begin{array}{c}\text { Urea formed } \\ (\mu \text { mole })\end{array} & \begin{array}{c}\mathrm{NH}_{3} \text { formed } \\ (\mu \text { mole })\end{array} \\ \text { Uric acid, 2.5 } & \mathbf{3 . 8 5} & \mathbf{9 \cdot 9} & \mathbf{2 \cdot 3} & - \\ \text { Uric acid, 20.0* } & - & - & \mathbf{2 0 \cdot 2 5} & \mathbf{3 9 \cdot 5} \\ \text { Glyoxylic acid, 10.0 } & \mathbf{9 \cdot 2} & \mathbf{1 8 \cdot 1} & 0 & 0\end{array}$

* In this experiment a suspension of organisms equivalent to $c .60 \mathrm{mg}$. dry wt./ml. was used.

It was therefore thought worthwhile in the present work to see whether a micro-organism which decomposed uric acid would also metabolize HDC. Free HDC, which was obtained by the addition of sodium chloride to the silver salt of HDC, was added to peptone water and inoculated with pseudomonad A; two-thirds of the HDC disappeared after 3 days while an uninoculated control of HDC in peptone water remained unchanged. Free HDC was also tested as substrate for pseudomonad $\mathbf{A}$ in manometric experiment. An uptake of oxygen was observed, but since the exact amount of HDC added was not known, the ratio $\mathrm{O}_{2}$ uptake/mole $\mathrm{HDC}$ used could not be calculated. 
Allantoin and allantoic acid. Pseudomonad A which had been grown on yeast extract medium + allantoin $(0.2 \%, \mathrm{w} / \mathrm{v})$ oxidized allantoin, allantoic acid and glyoxylic acid without lag, but uric acid and xanthine were oxidized only slowly (Fig. 2). This suggests that allantoic acid and glyoxylic acid are intermediates in the breakdown of allantoin by this organism, according to the concept of simultaneous adaptation (Stanier, 1947). When the organisms were grown on a medium containing uric acid they oxidized allantoin (Table 1) without lag; this oxidation required about 1 mole oxygen/mole substrate.

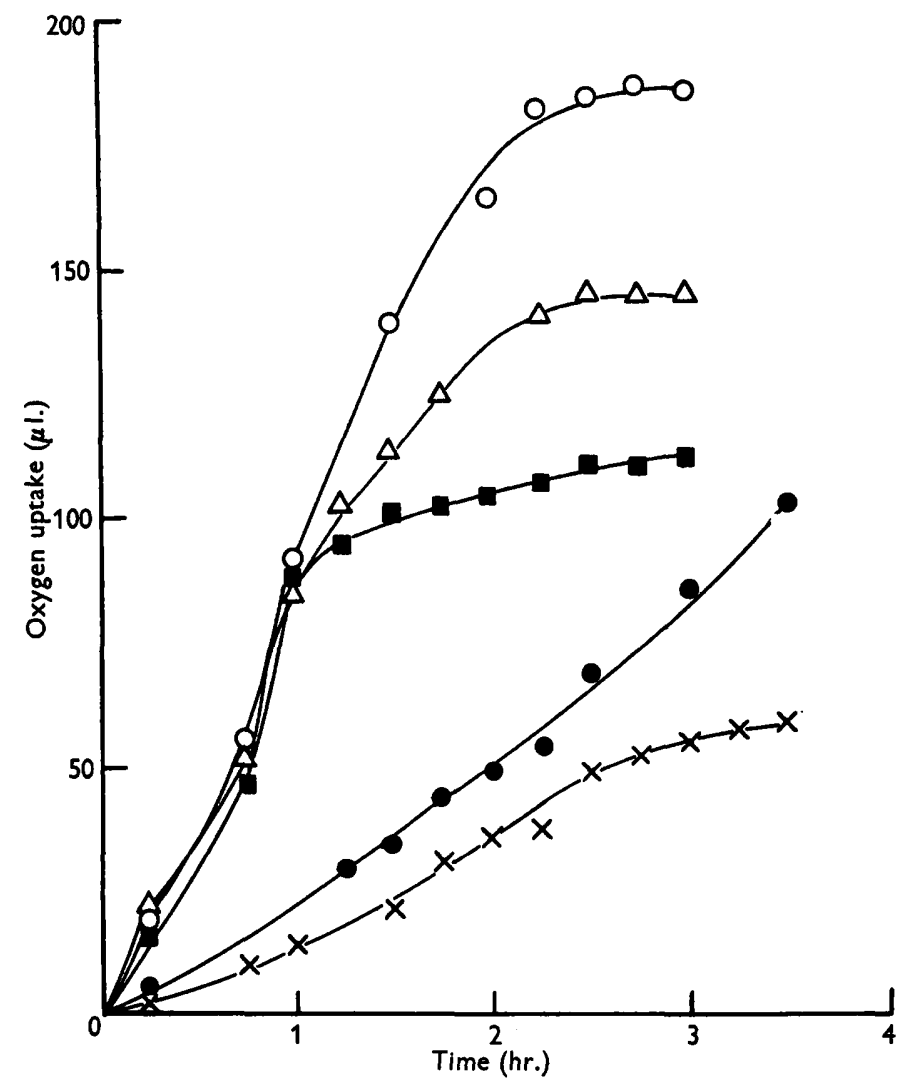

Fig. 2. Oxidation of various substrates by washed Pseudomonad A grown on allantoin. Each Warburg vessel contained the equivalent of $4 \mathrm{mg}$. (dry wt.) of organisms; $8 \mu \mathrm{mole}$ glyoxylic acid, $-\mathrm{O}-\mathrm{O}-; 6 \mu$ mole allantoic acid, $-\Delta-\triangle-; 5 \mu$ mole allantoin, $-\square-\square-$; $5 \mu$ mole xanthine, - ; $5 \mu$ mole uric acid, $-x-x-$. Other conditions as given in Table 1.

Glyoxylic acid and formic acid. Table 1 shows that during the oxidation of glyoxylic acid by the uric acid-grown organisms about 1 mole oxygen was taken up for every mole of glyoxylic acid which disappeared. During this oxidation 2 moles of carbon dioxide were evolved per mole glyoxylic acid which disappeared (Table 2) thus showing a complete oxidation.

When it was found that glyoxylic acid was completely oxidized by these pseudomonads the possible intermediates of its oxidation were considered. 
It seemed possible that oxalic acid (Franke \& Hahn, 1955) or formic acid (Campbell, 1954); Nakada \& Weinhouse, 1953) might be an intermediate. Oxalic acid was not oxidized, but formic acid was oxidized completely by these pseudomonads (Table 1 ). In every case 1 atom oxygen was taken up for each mole of formic acid which disappeared; carbon dioxide was evolved during the reaction.

\section{Anaerobic experiments}

Allantoin was shaken with uric acid-grown organisms (pseudomonad B) in Warburg flasks with a nitrogen gas phase. After $120 \mathrm{~min} .6 \mu$ mole allantoic acid and $1.2 \mu$ mole glyoxylic acid were formed from $10 \mu$ mole of allantoin which disappeared. When allantoic acid was used as substrate under the same conditions, $c$. $1 \mu$ mole glyoxylic acid was formed from $5 \mu$ mole allantoic acid which disappeared. The formation of glyoxylic acid was confirmed by paper chromatography. The fate of glyoxylic acid was also studied under anaerobic conditions. The concentration of glyoxylic acid markedly decreased; no change of gas volume occurred during this incubation. These results show that allantoin is metabolized by pseudomonad B to allantoic and glyoxylic acids. The glyoxylic acid formed may further be metabolized without $\mathrm{O}_{2}$ consumption.

\section{Effect of inhibitors}

The effect of various enzyme inhibitors on the oxidation of uric acid and some intermediates was investigated with uric acid-grown organisms (Table 3). Sodium azide and cyanide both inhibited the oxidation of uric acid, allantoin and glyoxylic acid by washed pseudomonad B organisms grown on uric acid. Colorimetric estimations showed that most of the allantoin and glyoxylic acid disappeared in the presence of the inhibitors, although the oxygen uptake was markedly inhibited.

Compounds resembling uric acid and allantoin in their chemical structure were tried as inhibitors; benzimidazole was effective, but hydantoin and glyoxaline had no effect. Iodoacetate and $p$-chloromercuribenzoate inhibited the oxidation of uric acid and glyoxylic acid. These inhibitors had no effect on the oxidation of formic acid.

2:4-Dinitrophenylhydrazine and semicarbazide, which react with carbonyl groups, inhibited the oxidation of uric acid.

While using the Thunberg tube technique to study the decomposition of glyoxylic acid it was observed that almost no reaction took place in the presence of $c .10^{-4} \mathrm{M}$-methylene blue. Manometric experiments showed that the methylene blue inhibited oxygen uptake with glyoxylic acid as substrate, while that with formic acid was unaffected (Table 3).

It is known that arsenite inhibits oxidative decarboxylation processes. Because of the possibility that glyoxylic acid was metabolized by such a reaction, arsenite was tested as an inhibitor; oxygen uptake with glyoxylic acid or formic acid as substrate was not thereby affected.

According to Tolbert, Clagett \& Burris (1949) oxalic acid inhibits the oxidation of glyoxylic acid. Various concentrations of oxalic acid $\left(10^{-2}\right.$ to 
$2 \times 10^{-1} \mathrm{M}$ ) were used but no inhibition of oxygen uptake was observed with allantoin, glyoxylic, formic or uric acids as substrate.

Borate inhibits xanthine oxidase (Roush \& Norris, 1950) and this enzyme also oxidizes aldehydes. Borate at $10^{-1} \mathrm{M}$ inhibited oxygen uptake with glyoxylic acid by pseudomonad B, but had no effect with formic acid as substrate (Table 3).

Table 3. Effect of various inhibitors on $\mathrm{O}_{2}$ uptake of uric-acid-grown pseudomonads

$0.5 \mathrm{ml}$. inhibitor solution was used. Other conditions as in Table 1.

\begin{tabular}{|c|c|c|c|c|c|}
\hline & & & Oxidation & substrat & \\
\hline & Concentration & $\begin{array}{l}\text { Uric } \\
\text { acid }\end{array}$ & Allantoin & $\begin{array}{l}\text { Glyoxy- } \\
\text { lic acid }\end{array}$ & $\begin{array}{c}\text { Formic } \\
\text { acid }\end{array}$ \\
\hline Inhibitor & $\begin{array}{c}\text { of inhibitor } \\
\text { (M) }\end{array}$ & Degree c & of inhibitio & $\mathrm{n}$ of $\mathrm{O}_{2} \mathrm{u}$ & take (\%) \\
\hline Azide & $5 \times 10^{-3}$ & 20 & 40 & 40 & $\mathbf{5 0}$ \\
\hline Azide & $5 \times 10^{-2}$ & 80 & 100 & - & - \\
\hline Cyanide & $5 \times 10^{-3}$ & 30 & 40 & - & - \\
\hline Cyanide & $5 \times 10^{-2}$ & 100 & 100 & - & - \\
\hline Benzimidazole & $1 \times 10^{-2}$ & $\mathbf{5 0}$ & - & - & 一 \\
\hline Benzimidazole & $1 \times 10^{-1}$ & - & 100 & - & - \\
\hline Hydantoin & $2 \times 10^{-1}$ & $\mathbf{0}$ & - & - & - \\
\hline Glyoxaline & $1 \times 10^{-2}$ & $\mathbf{0}$ & - & - & - \\
\hline Iodoacetate & $5 \times 10^{-3}$ & 100 & 一 & 80 & $\mathbf{0}$ \\
\hline$p$-Chloromercuribenzoate & $5 \times 10^{-3}$ & 100 & - & 100 & $\mathbf{0}$ \\
\hline 2:4-Dinitrophenylhydrazine & $2 \times 10^{-2}$ & 100 & - & - & - \\
\hline Semicarbazide & $5 \times 10^{-2}$ & 100 & - & - & - \\
\hline Methylene blue & $3 \times 10^{-4}$ & - & - & 60 & 0 \\
\hline Arsenite & $5 \times 10^{-3}$ & - & - & $\mathbf{0}$ & $\mathbf{0}$ \\
\hline Oxalate & $1 \times 10^{-2}$ to $2 \times 10^{-1}$ & $\mathbf{0}$ & $\mathbf{0}$ & $\mathbf{0}$ & $\mathbf{0}$ \\
\hline Borate & $1 \times 10^{-1}$ & - & - & 75 & $\mathbf{0}$ \\
\hline
\end{tabular}

From the results summarized in Table $\mathbf{3}$, it may be concluded that one of the steps in the oxidation of uric acid is catalysed by an - $\mathrm{SH}$ enzyme which is inhibited by iodoacetate or $p$-chloromercuribenzoate (cf. Scheer \& Scheer, 1943, who found that cysteine activated the uricase of liver). The degradation of glyoxylic acid does not seem to be an oxidative decarboxylation process, for it was not affected by arsenite.

\section{Oxidation of other compounds by the pseudomonads}

Purines. Uric acid-grown organisms (pseudomonad A) were tested for ability to oxidize various purines. According to spectrophotometric measurements xanthine disappeared completely, a partial disappearance of hypoxanthine and adenine took place, while guanine was scarcely affected. Manometric experiments gave similar results (Table 4).

Pyrimidines. Uric acid-grown organisms (pseudomonad A) showed no significant oxygen uptake with alloxan or uracil as substrates.

Imidazoles. Hydantoin, parabanic acid, glyoxaline and benzimidazole were tested as oxidation substrates for uric acid-grown organisms (pseudomonad A); 
no significant oxygen uptake was observed with any of these compounds. The possibility of a hydrolytic degradation of these compounds was considered, but no increase in the amounts of urea or ammonia were observed after incubating the organisms with hydantoin or parabanic acid.

Table 4. Oxidation of various substrates by uric acid-grown pseudomonads

Experimental conditions as given in Table $1 ; 5 \mu$ mole substrate used. Duration of experiment: $60 \mathrm{~min}$.

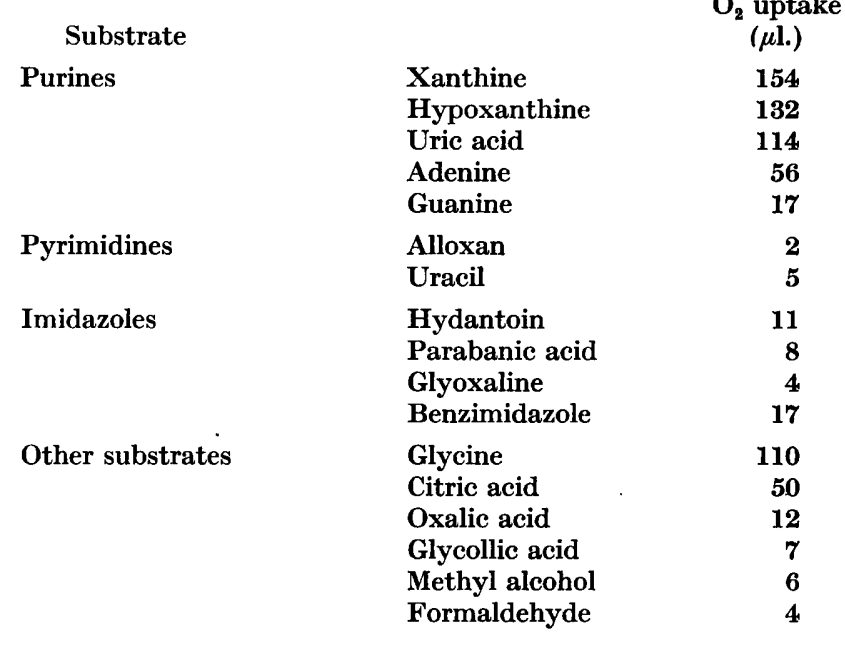

Other substances. Formaldehyde, methanol and oxalic acid were not oxidized (uric acid-grown pseudomonads $\mathbf{A}$ and $\mathbf{B}$ ), nor was glycollic acid (pseudomonad B). Glycine and citric acid were oxidized by washed uric acid-grown organisms (pseudomonads A and B).

\section{DISCUSSION}

Simultaneous adaptation experiments and the tests performed under anaerobic conditions, by which the degradation products of uric acid were demonstrated, support the view that uric acid is completely degraded by the pseudomonads from deep-litter through the pathway shown in Fig. 1. Campbell (1954) isolated a pseudomonad from San Francisco Bay mud which oxidized allantoin completely. This organism also oxidized uric acid to carbon dioxide and urea; glyoxylic acid was an intermediate in the oxidation, and by the use of carboxyl-labelled glyoxylic acid it was found that the carboxyl carbon was converted to formate (Campbell, 1955). Franke \& Hahn (1955) showed that uric acid was oxidized to oxalic acid, via glyoxylic acid, by resting.

\section{Pseudomonas aeruginosa.}

With the pseudomonads tested (A and B) in the present work no accumulation of oxalic acid was found, nor were oxalic acid or glycollic acid oxidized. These observations, together with the uptake of 2 atoms of oxygen/mole glyoxylic acid which disappeared, would seem to eliminate the possibility of the pathway described by Franke \& Hahn (1955), in the present pseudomonads. 
Under anaerobic conditions, or in the presence of azide, glyoxylic acid disappeared without consumption of oxygen; therefore a direct oxidation of glyoxylic acid to formate and $\mathrm{CO}_{2}$ seems excluded. The fact that arsenite, a known inhibitor of oxidative decarboxylation (Baldwin, 1952), had no effect on the oxidation of glyoxylic acid, is also evidence against the occurrence of this reaction. Indirect evidence against an oxidative decarboxylation is also given by the fact that the degradation of glyoxylic acid by the pseudomonads studied was not affected by the addition of oxalic acid (contrary to the effect of oxalic acid on the oxidative decarboxylation of glyoxylic acid by plant tissue; Tolbert et al. 1949). This conclusion agrees with the findings of Campbell (1954) and suggests that glyoxylic acid metabolism by the present pseudomonads may occur by a mechanism like the phosphoroclastic splitting of pyruvic acid (Chantrenne \& Lipmann, 1950), namely: R.CO.COOH $\rightarrow$ R.CO - enzyme + $\mathrm{HCOOH}$; or by a condensation of glyoxylic acid with succinic acid to form isocitric acid (Saz, 1954) which might then be oxidized.

The author wishes to thank Prof. B. C. J. G. Knight for extending the hospitality of his department and for originally suggesting this problem. Thanks are further due to Professor Knight and Dr L. J. Zatman for many helpful and stimulating discussions, and to the late Dr T. Richards and to Dr M. E. Rhodes for their help in classifying the organisms. The author is grateful to the Friends of the Hebrew University for the award of a Humanitarian Trust Fellowship.

\section{REFERENCES}

Baldwin, E. (1952). Dynamic aspects of Biochemistry, 2nd ed. Cambridge University Press.

Block, R. J., Durrum, E. L. \& Zweig, G. (1955). A Manual of paper chromatography and paper electrophoresis. New York: Academic Press.

Brown, G. B., Roll, P. M. \& Cavalieri, L. F. (1947). The in vivo oxidation of uric acid. J. biol. Chem. 171, 835.

CAmpbell, L. L. Jr. (1954). The mechanisms of allantoin degradation by a Pseudomonas. J. Bact. 68, 598.

Campbell, L. L. Jr. (1955). Oxidative degradation of uric acid by cell extracts of a pseudomonas. Biochim. biophys. Acta, 18, 160.

Cavalieri, L. F. \& Brown, G. B. (1948). The mechanism of the oxidation of uric acid studied with isotopic nitrogen as a tracer. J. Amer. chem. Soc. 70, 1242.

Chantrenne, H. \& Lipmann, F. (1950). Coenzyme A dependence and acetyl donor function on the pyruvate-formate exchanges system. J. biol. Chem. 187, 757 .

Dalgleish, C. E. \& Neuberger, A. (1954). J. chem. Soc. 3407.

Davidson, J. N. (1938). The purification of uricase. Biochem. J. 32, 1386.

Di Carlo, F. J., Schultz, A. S. \& Kent, A. M. (1953). The mechanism of allantoin catabolism by yeast. Arch. Biochem. 44, 468.

Franke, W., Taha, E. E. M. \& Krieg, L. (1952). Purinoxydierende Fermente aus Schimmelpilzen. Arch. Mikrobiol. 17, 255.

Franke, W. \& Hahn G. E. (1955). Untersuchungen zum bakteriellen Purinabbau Hoppe-Seyl. Z. 299, 15.

Hermanowicz, W. (1948). Formation of allantonic acid from allantoin. Roczniki Chem. 22, 159. (Taken from Chem. Abstr. (1950) 44, 1418/h.)

Hотснкіss, R. D. (1948). The quantitative separation of purines and nucleosides by paper chromatography. J. biol. Chem. 175, 315. 
KLemperer, F. W. (1945). Enzymatic oxidation of uric acid. J. biol. Chem. 160, 111 .

Laskowski, M. (1951). In The Enzymes, 1 (2), 946; ed. by Sumner, J. B. \& Myrback, K. New York: Academic Press Inc.

MA, T. S. \& ZuAZAGA, G. (1942). Micro-Kjeldahl determination of nitrogen. A new indicator and an improved rapid method. Industr. Engng Chem. (Anal.), 14, 280.

MARKham, R. (1942). A steam distillation apparatus suitable for micro-Kjeldahl analysis. Biochem. J. 36, 790.

NAKada, H. J. \& Weinhouse, E. S. (1953). Studies of glycine oxidation in rat tissues Arch. Biochem. 42, 257.

Praetorius, E. (1949). An enzymic method for the determination of uric acid by ultraviolet spectrophotometry. Scand. J. clin. Lab. Invest. 1, 222.

SAz, H. J. (1954). The enzymic formation of glyoxylate and succinate from tricarboxylic acids. Biochem. J. 58, xx.

Roush, A. \& Norris, E. R. (1950). The inhibition of xanthine oxidase by borates. Arch. Biochem. 29, 244.

Scheer, B. T. \& Scheer, M. A. R. (1943). The activation of uricase by cysteine. J. biol. Chem. 150, 359.

Schuler, W. \& Reindel, W. (1932). Die Urikolyse. Hoppe-Seyl. Z. 208, 248.

Stanier, R. Y. (1947). Simultaneous adaptation: A new technique for the study of metabolic pathways. J. Bact. 54, 339.

StapP, C. (1920). Botanische Untersuchung einiger neuer Bakterien-species, welche mit reiner Harnsäure oder Hippursäure als alleinigem organischen Nährstoff auskommen. $\mathrm{Zbl}$. Bakt. (2 Abt.), 51, 1.

Tolbert, N. E., Clagett, C. O. \& Burris, R. H. (1949). Products of the oxidation of glycollic acid and L-lactic acid by enzymes from tobacco leaves. J. biol. Chem. $181,905$.

Umbreit, W. W., Burris, R. H., \& Stauffer, J. F. (1949). Manometric Techniques and Tissue Metabolism. Minneapolis, U.S.A.: Burgess Publ. Co.

Young, E. G. \& Conway, C. F. (1942). On the estimation of allantoin by the RiminiSchryver reaction. J. biol. Chem. 142, 839.

(Received 12 September 1956) 